\title{
Determination of Gemifloxacin in human plasma by high performance liquid chromatography using Ultra Violet detector and its application to a bioequivalence study
}

\author{
Syed Husain Hashemi Mousavi ${ }^{1}$
}

${ }^{I}$ Department of Chemistry, Faculty of Engineering, South Tehran Branch, Islamic Azad University, Tehran, Iran

\begin{abstract}
A liquid chromatography method was developed and validated for the determination of gemifloxacin in human plasma using chloramphenicol as internal standard to achieve lower quantification limit. Acetonitrile was used to precipitated and extracted analyte and internal standard from plasma by Protein Precipitation. Analysis was performed isocratically on $\mathrm{C}_{18}$ column using $25 \%$ acetonitrile and $75 \% 0.02$ $\mathrm{M}$ phosphate buffer as mobile phase. The method was demonstrated to be linear from $0.003 \mu \mathrm{g} / \mathrm{mL}$ to $5 \mu \mathrm{g} / \mathrm{mL}$ with the lower limit of quantitation of $0.003 \mu \mathrm{g} / \mathrm{mL}$. The method was successfully applied for the bioequivalence study of gemifloxacin after a single oral administration of $320 \mathrm{mg}$ gemifloxacin mesylate tablets to 12 healthy volunteers.
\end{abstract}

Keywords: Gemifloxacin/determination. Bioequivalence. Plasma. HPLC.

\section{INTRODUCTION}

Gemifloxacin mesylate is a synthetic broadspectrum antibacterial agent for oral administration. Gemifloxacin, a compound related to the fluoroquinolone class of antibiotics, is available as the mesylate salt in the sesqui hydrate form. Chemically, gemifloxacin is $(R, S)$-7[(4Z)-3-(aminomethyl)-4-(methoxyimino)-1pyrrolidinyl]-1-cyclopropyl-6-fluoro-1,4-dihydro-4oxo1,8-naphthyridine-3-carboxylic acid (Figure 1). It is used in the treatment of acute bacterial exacerbation of chronic bronchitis and mild-to-moderate pneumonia. Gemifloxacin has been shown to be active against most strains of microorganisms. It is particularly active against Gram-positive organisms including penicillin, macrolide, and quinolone resistant Streptococcus pneumoniae (Calvo, Gimenez, 2002; Oh et al., 1996; Johnson et al., 1999; Berry et al., 2000; Hardy et al., 1999). Gemifloxacin acts by inhibiting DNA synthesis through the inhibition of both deoxyribonucleic acid (DNA) gyrase and topoisomerase IV (TOPO IV), which are essential for bacterial growth.

Correspondence: S. H. H. Mousavi. Department of Chemistry, Faculty of Engineering, South Tehran Branch, Islamic Azad University, Tehran, Iran, P. O. Box 11365-4435. Phone number: 0989038400292, 09821 33030505. E-mail: hashemimosavi@yahoo.com
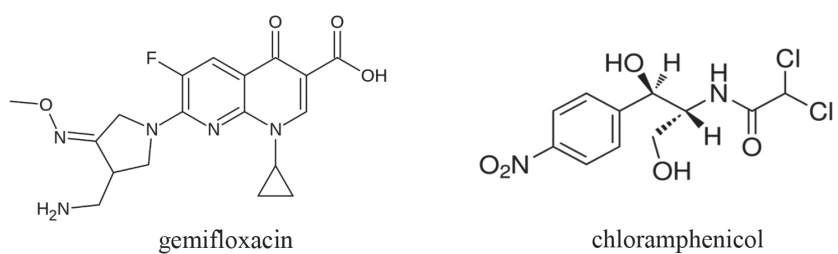

FIGURE 1 - Chemical structure of gemifloxacin and chloramphenicol.

Literature survey revealed that analytical methods have been reported for the estimation of gemifloxacin, they include high performance liquid chromatography tandem mass spectrometry (Doyle et al., 2000; Ramji et al., 2001), microchip electrophoresis (Seung et al., 2004), chiral high performance liquid chromatography (Hee et al., 2009) and chiral countercurrent chromatography (Eun, Yoo-Mo, Doo, 2004; Myung et al., 2002). Simple and sensitive ion pairing spectrophotometric methods have been described for the assay of gemifloxacin mesylate by Marothu and Dannana (2008). Barbosa and co-workers (Barbosa et al., 1997) studied dissociation constants of series of compounds including diuretics and quinolones in several acetonitrile: water mixtures, high performance liquid chromatography by UV detector (Sultana et al., 2011), with fluorescence detection (Allen et al., 2000b; Al-Hadiya et al., 2010), high performance thin-layer 
chromatography (HPTLC) with fluorescence detection (El-Koussi et al., 2014). The aim of the present study was to establish an efficient, reliable, accurate, sensitive and reproducible method for the application in bioequivalence study of gemifloxacin tablets $320 \mathrm{mg}$.

\section{MATERIAL AND METHODS}

\section{Subjects}

Twelve healthy male and female volunteers with mean weight of $65.6 \pm 11 \mathrm{~kg}$, mean height of $164.6 \pm 7.8$ $\mathrm{cm}$ and mean age of $32.2 \pm 8.4$ years were enrolled into the study. All volunteers had normal paraclinical parameters.

Exclusion criteria were as follows: Consumption of tobacco in any form in study day, Addiction to alcohol or history of any drug abuse, History of kidney or liver dysfunction, History of jaundice in the past 6 months, History of drug allergy to the test drug or any chemically similar to the drug under investigation, Administration / intake of any prescription or OTC medication for 2 weeks before the study, Patient suffering from any chronic illness such as arthritis and asthma, Subject suffering from any psychiatric (acute or chronic) illness, Participation in any bioavailability / bioequivalence study in the past 12 weeks, Intake of barbiturates or any enzyme - inducing drug in the past 3 months and HIV positive volunteers.

\section{Study design and blood samples}

This was a laboratory-blind, single-dose, randomized, 2-way cross-over study with a wash-out period of 7 days between the clinic (blood sampling) days to compare the pharmacokinetics of gemifloxacin (test product) and Factive ${ }^{\circledR}$ (reference product).

Body temperature, heart rate and blood pressure were recorded before drug administration on clinic days. Heart rate and blood pressure recordings were repeated at approximately 4 and 6 hours after drug administration. After insertion of an indwelling venous cannula, pre-dose blood samples had been drawn. Six Subjects received Gemifloxacin Tablets (test product, $320 \mathrm{mg}$ ) and the other six subjects received reference Factive ${ }^{\circledR}$ Tablets $(320 \mathrm{mg}$ ) with $240 \mathrm{~mL}$ drinking water. The only food allowed was standardized meals served 6 hours and a standardized breakfast 3 hours after drug administration. No restrictions on the intake of food and fluid applied after the subjects had been discharged from the clinic. Gemifloxacin was assayed in plasma samples collected from 12 subjects, and data from 12 subjects were evaluated. Venous blood samples will be collected into heparinized, glass tubes, labeled as per-treatment phase, according to the following time schedule: before drug administration and at 0.33 , $0.67,1,1.33,1.67,2,2.33,2.67,3,3.5,4,6,8,10,12$ and 24 hours after drug administration (18 samples per subject per profile period).

\section{Bioanalytical methods}

A liquid chromatography method was developed and validated for the determination of gemifloxacin in human plasma as per FDA and ICH guidelines. Extraction procedure as described below.

$100 \mu \mathrm{L}$ chloramphenicol $30 \mathrm{mg} / \mathrm{L}$ is added to 1500 $\mu \mathrm{L}$ of plasma as an internal standard and mix. $1500 \mu \mathrm{L}$ acetonitrile is added to plasma and is vortexed for 10 second then $100 \mu \mathrm{L}$ sulfuric acid $2 \mathrm{M}$ is added. After mixing, sodium chloride is added and centrifuge at 4000 rpm for 10 minutes. The organic phase is dried and then reconstitute with $100 \mu \mathrm{L}$ of mobile phase. $50 \mu \mathrm{L}$ of this sample was injected into the HPLC.

\section{Chromatographic conditions}

The Knuer EA4300 HPLC pump and Knuer E4310 detector were used for bioanalytical assay of standards and human samples. Mobile phase consisted of phosphate buffer $(0.02 \mathrm{M})$ and acetonitrile $(75: 25)$ and the $\mathrm{pH}$ of mixture adjust to 3.0 with phosphoric acid and pumped at the flow rate of $1 \mathrm{~mL} / \mathrm{min}$ through the $250 \mathrm{~mm} \mathrm{C}_{18}$ column. The wavelength of detector for monitoring of peaks was $275 \mathrm{~nm}$. Representative chromatograms of blank plasma, plasma of one volunteer and standard chromatogram are shown in Figure 2.

\section{Calibration curve}

Standard samples were prepared as mentioned before (Bioanalytical Methods). The method has good linearity $(\mathrm{r}>0.999)$ over the concentration rang $0.003-5.000 \mu \mathrm{g} /$ $\mathrm{mL}$. The equation of line was $\mathrm{y}=0.53199 \mathrm{x}+0.02165$ and the limit of quantification was $0.003 \mu \mathrm{g} / \mathrm{mL}$. Inter-day and intra-day precision and accuracy and stability of this method shows that this is the validated method for determination of gemifloxacin in human plasma.

\section{Precision and accuracy}

Accuracy is measured as \% bias and precision is measured as coefficient of variation $(\% \mathrm{CV})$.

For the assignment of a valid calibration range bias is taken as measure of accuracy and coefficient of variation $(\% \mathrm{CV})$ is taken as measure of precision. Intra-day accuracy and precision for a valid range must be within $15 \%$ but within $20 \%$ at the lower limit of quantification.

Summarize inter-day and intra-day accuracy and precision during assay validation are in Table I to II. 

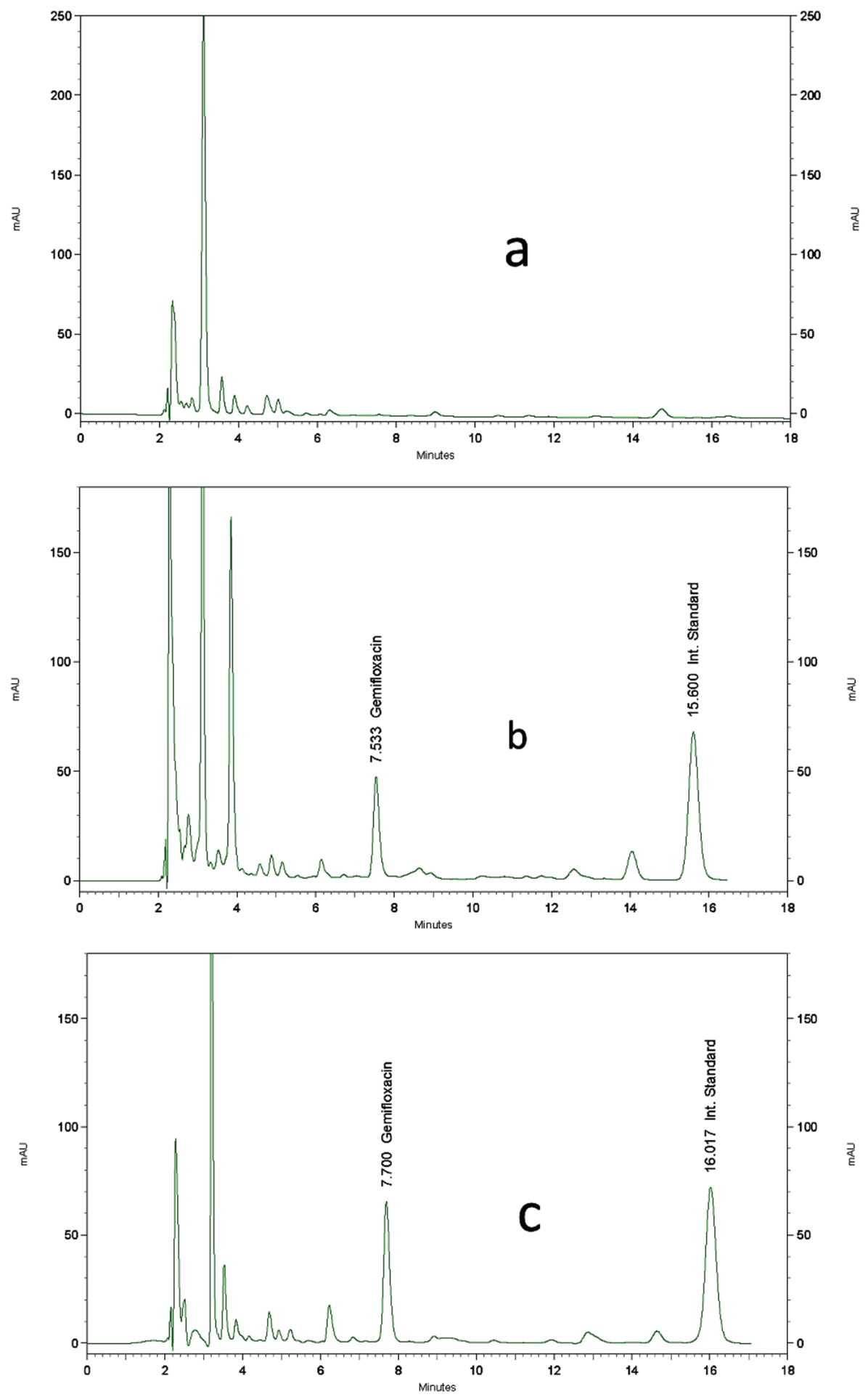

FIGURE 2 - Representative chromatograms of a) blank plasma b) standard chromatogram $(0.7 \mu \mathrm{g} \mathrm{mL}-1)$ and c) plasma of one volunteer (3 hours).

\section{Stability}

The stability of gemifloxacin in plasma was investigated in samples obtained from a spiked plasma at two concentrations. Three plasma samples were analysed three months after storage at $-20{ }^{\circ} \mathrm{C}$.
Analysis of long-term storage stability, three cycle freeze-thaw stability, bench top stability, stock solution stability shows gemifloxacin was stable in plasma for at least three months when stored at $-20^{\circ} \mathrm{C}$ (Table III). 
TABLE I - Inter-day precision

\begin{tabular}{cccc}
\hline & $\mathbf{0 . 0 0 3 0} \boldsymbol{\mu} \mathbf{g} / \mathbf{m L}$ & $\mathbf{1 . 0} \boldsymbol{\mu} \mathbf{g} / \mathbf{m L}$ & $\mathbf{5 . 0} \boldsymbol{\mu \mathbf { g } / \mathbf { m L }}$ \\
\hline 1 & 0.0025 & 1.1 & 5.0 \\
2 & 0.0032 & 1.1 & 5.0 \\
3 & 0.0028 & 1.1 & 5.1 \\
4 & 0.0034 & 0.9 & 5.1 \\
5 & 0.0036 & 1.1 & 5.1 \\
Average & 0.0031 & 1.06 & 5.06 \\
RSD & 14.4 & 8.4 & 1.1 \\
\hline
\end{tabular}

TABLE II - Intra-day precision and accuracy

\begin{tabular}{cccc}
\hline & $\mathbf{0 . 0 0 3 0} \boldsymbol{\mu g} / \mathbf{m L}$ & $\mathbf{1 . 0} \boldsymbol{\mu g} / \mathbf{m L}$ & $\mathbf{5 . 0} \boldsymbol{\mu g} / \mathbf{m L}$ \\
\hline 1 & 0.0029 & 1.1 & 5.0 \\
2 & 0.0034 & 1.1 & 5.1 \\
3 & 0.0025 & 0.9 & 5.0 \\
4 & 0.0024 & 1.0 & 4.9 \\
5 & 0.0032 & 1.1 & 5.1 \\
Average & 0.0029 & 1.04 & 5.02 \\
RSD & 15.0 & 8.6 & 1.7 \\
Accuracy & 96.7 & 104 & 100.4 \\
\hline
\end{tabular}

\section{RESULTS}

Plasma sample from twelve healthy volunteers at $0,0.33,0.67,1,1.33,1.67,2,2.33,2.67,3,3.5,4,6,8$, 10,12 and 24 hours were collected and were analyzed as mentioned before in section "Bioanalytical Methods". The mean pharmacokinetic parameters such as maximum concentration $\left(\mathrm{C}_{\max }\right)$, time to reach $\mathrm{C}_{\max }\left(\mathrm{T}_{\max }\right)$, area under curve from time zero to 24 hours $\left(\mathrm{AUC}_{0-24}\right)$ and area under curve from time zero to infinite $\left(\mathrm{AUC}_{0-\infty}\right)$ are presented in the Table IV. The mean plasma volunteers curve is shown in Figure 3.

The $90 \%$ confidence intervals for the "test/reference"

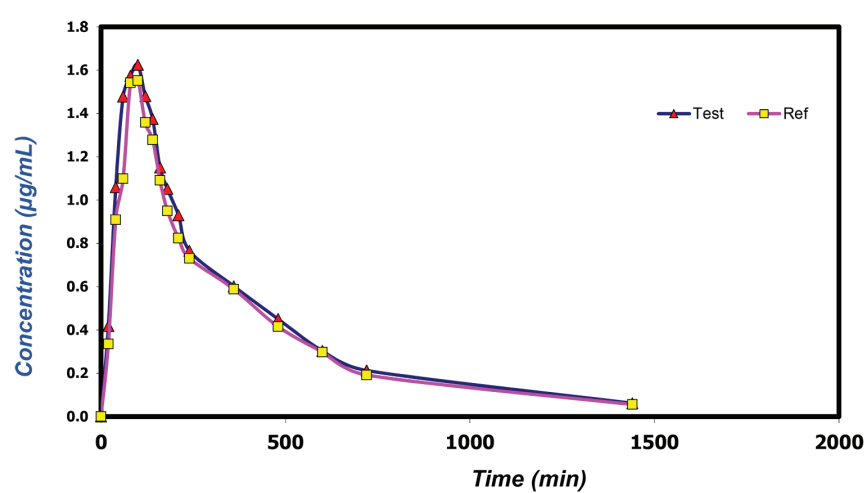

FIGURE 3 - Mean plasma volunteers curve.

mean ratio of the pharmacokinetic variables Cmax, Tmax, AUC0-10, AUC0-Inf, fall within the conventional bioequivalence range of $80 \%$ to $125 \%$.

The results of this study indicate that the test product with assay of $105.8 \%$ for test product of Gemifloxacin is bioequivalent to the reference product $\left(\right.$ Factive $\left.^{\circledR}\right)$ with respect to both the rate and extent of absorption of Gemifloxacin.

Under Medication Guide of Factive ${ }^{\circledR}$ tablets which has been approved by the U.S. Food and Drug Administration it was reported that following repeat oral doses of $320 \mathrm{mg}$ of Factive ${ }^{\circledR}$ tablets to healthy subjects (FACTIVE ${ }^{\circledR}$ Tablets-FDA), and in another study "The effect of food on the bioavailability of oral gemifloxacin in healthy volunteers" (Allen et al., 2000a, the pharmacokinetics parameters were compare with this study in Table V. Comparison of this results with our study shows its similar to other studies.

\section{CONCLUSION}

It is thus concluded that the proposed method is simple, cost effective, accurate, safe and precise. A specific LC method, with a single step Protein Precipitation procedure, has been developed and validated (as per FDA and ICH forguidelines) for

TABLE III - Gemifloxacin stability

\begin{tabular}{|c|c|c|c|c|c|c|c|c|}
\hline \multirow{2}{*}{$\begin{array}{l} \\
\text { Spiked } \\
\text { concentration } \\
(\mu \mathrm{g} / \mathrm{mL})\end{array}$} & \multicolumn{2}{|c|}{$\begin{array}{c}\text { long-term storage stability } \\
\text { (three months) }\end{array}$} & \multicolumn{2}{|c|}{$\begin{array}{c}\text { freeze-thaw stability } \\
\text { (three cycle) }\end{array}$} & \multicolumn{2}{|c|}{ bench top stability } & \multicolumn{2}{|c|}{ stock solution stability } \\
\hline & 0.0030 & 5.0 & 0.0030 & 5.0 & 0.0030 & 5.0 & 0.0030 & 5.0 \\
\hline Average & 0.0027 & 4.9 & 0.0028 & 5.0 & 0.0031 & 5.0 & 0.0030 & 4.9 \\
\hline Accuracy & 90.0 & 98 & 93.3 & 100 & 103.3 & 100 & 100.0 & 98 \\
\hline$\% \mathrm{CV}$ & 0.00152 & 0.05773 & 0.00115 & 0.11547 & 0.00058 & 0.05773 & 0.00058 & 0.05774 \\
\hline
\end{tabular}


Determination of Gemifloxacin in human plasma by high performance liquid chromatography using Ultra Violet detector

TABLE IV - Pharmacokinetic parameters of the gemifloxacin $320 \mathrm{mg}$ test and reference

\begin{tabular}{|c|c|c|c|c|c|}
\hline & \multicolumn{2}{|c|}{ Mean } & \multirow{2}{*}{$\begin{array}{c}\text { Confidence } \\
\text { interval }\end{array}$} & \multicolumn{2}{|c|}{ Pvalue } \\
\hline & Test & Reference & & T-test & ANOVA \\
\hline $\mathrm{AUC}_{0 \rightarrow \mathrm{t}}$ & $588.98 \pm 155.60$ & $543.59 \pm 152.79$ & $103.6 \%-121.34 \%$ & 0.478 & 0.478 \\
\hline $\mathrm{AUC}_{0 \rightarrow \infty}$ & $701.28 \pm 178.09$ & $667.90 \pm 189.27$ & $100.5 \%-118.48 \%$ & 0.661 & 0.661 \\
\hline $\mathrm{C}_{\max }(\mu \mathrm{g} / \mathrm{mL})$ & $1.95 \pm 0.50$ & $1.82 \pm 0.57$ & $103.3 \%-116.99 \%$ & 0.579 & 0.579 \\
\hline $\mathrm{T}_{\max }(\min )$ & $71.67 \pm 24.80$ & $78.33 \pm 31.29$ & $88.67 \%-109.65 \%$ & 0.569 & 0.569 \\
\hline $\mathrm{K}_{\mathrm{el}}$ & $0.00220 \pm 0.00081$ & $0.00214 \pm 0.00082$ & $88.47 \%-102.29 \%$ & 0.872 & 0.872 \\
\hline $\mathrm{T}_{1 / 2}(\min )$ & $381.823 \pm 224.907$ & $396.169 \pm 229.044$ & $102.0 \%-115.05 \%$ & 0.884 & 0.884 \\
\hline
\end{tabular}

TABLE V- Comparison of pharmacokinetic parameters with other studies

\begin{tabular}{lccc}
\hline & This study & Allen et al. study & Factive $^{\circledR}$ study \\
\hline $\mathrm{AUC}_{0 \rightarrow 24}$ & $588.98 \pm 155.60$ & & $595.8 \pm 184.2$ \\
$\mathrm{AUC}_{0 \rightarrow \infty}$ & $701.28 \pm 178.09$ & $454.2 \pm 139.8$ & \\
$\mathrm{C}_{\max }(\mu \mathrm{g} / \mathrm{mL})$ & $1.95 \pm 0.50$ & $1.21 \pm 0.33$ & $1.61 \pm 0.51$ \\
$\mathrm{~T}_{\max }(\mathrm{min})$ & $71.67 \pm 24.80$ & $90(60-240)$ & $30-120$ \\
\hline
\end{tabular}

the determination of gemifloxacin in human plasma supporting a pharmacokinetic and bioequivalence study comparison of other study (FACTIVE ${ }^{\circledR}$ Tablets-FDA). The statistical analysis demonstrated that none of the parameters accepted for drug bioavailability $\left(\mathrm{AUC}_{0-\mathrm{t}}\right.$ and $\mathrm{C}_{\max }$ ) were not significantly different between the treatments for the single dose data. Moreover, it indicated that the two pharmaceutical products showed similar bioavailability profiles and therefore are considered bioequivalent with regard to the extent and rate of absorption and, interchangeable as well, for clinical and therapeutic purposes.

The proposed method to analyze gemifloxacin in plasma by HPLC with UV detection happens to be first of its kind described so far in the literature. This new method with low LOQ $(0.003 \mu \mathrm{g} / \mathrm{mL})$ will be helps for carrying out pharmacokinetic study of gemifloxacin in laboratories that lack sophisticated analytical instrument of LC-MS/MS.

\section{REFERENCES}

Al-Hadiya BMH, Khady AA, Mostafa GAE. Validated liquid chromatographic-fluorescence method for the quantitation of gemifloxacin in human plasma. Talanta. 2010;83(1):110-116.

Allen A, Bygate E, Clark D, Lewis A, Pay V. The effect of food on the bioavailability of oral gemifloxacin in healthy volunteers. Antimicrob Agents Chemother. 2000a;16(1):45-50.
Allen A, Bygate E, Oliver S, Johnson M, Ward C, Cheon A, Choo YS, Kim IC. Pharmacokinetics and tolerability of gemifloxacin (SB-265805) after administration of single oral doses to healthy volunteers. Antimicrob Agents Chemother. 2000b;44(6):1604-1608.

Barbosa J, Marqués I, Fonrodona G, Barrón D, Bergés R. Factor analysis applied to correlation between acidity constants of series of diuretics, quinolones and buffers, with solvatochromic parameters in water-acetonitrile mixtures. Anal Chim Acta. 1997;347(3):385-393.

Berry V, Page R, Satterfield J, Singley C, Straub R, Woodnutt G. Comparative in vivo activity of gemifloxacin in a rat model of respiratory tract infection. J Antimicrob Chemother. 2000;45(Suppl 1):79-85.

Calvo A, Gimenez MJ. Ex vivo serum activity (killing rates) after Gemifloxacin $320 \mathrm{mg}$ versus Trovafloxacin $200 \mathrm{mg}$ single doses against ciprofloxacin-susceptible and -resistant streptococcus pneumoniae. Int J Antimicrob Agents. 2002;20:144-6.

Doyle E, Fowles SE, Mcdonnell DF, Mccarthy R, White SA. Rapid determination of gemifloxacin in human plasma by high performance liquid chromatography-tandem mass spectrometry. J Chromatogr B. 2000;746(2):191-8.

El-Koussi WM, Atia NN, Mahmoud AM, El-Shabouri SR. HPTLC method for direct determination of gemifloxacin mesylate in human plasma. J Chromatogr B. 2014;967:98-101. 
Eun SK, Yoo-Mo K, Doo SC. Chiral counter-current chromatography of gemifloxacin guided by capillary electrophoresis using $(+)-(18$-crown-6)-tetracarboxylic acid as a chiral selector. J Chromatogr A. 2004;1045(1-2):119-124.

FACTIVE $^{\circledR}$ Tablets FDA. 2008. 34p. Available from: https://www.accessdata.fda.gov/drugsatfda_docs/ label/2008/021158s013lbl.pdf.

Hardy D, Amsterdam D, Mandell L, Rotstein C. Comparative in vitro activity of gemifloxacin, moxifloxacin, trovafloxacin, sparfloxacin, grepafloxacin, ofloxacin, ciprofloxacin and other antimicrobial agents against bloodstream isolates of Grampositive cocci. J Antimicrob Chemother. 1999;44(3):802-5.

Hee JC, Hwan SC, Sang CH, Myung HH. HPLC of fluoroquinolone antibacterials using chiral stationary phase based on enantiomeric (3,3'-diphenyl-1,1'-binaphthyl)-20crown-6. J Sep Sci. 2009;32(4):536-541.

Johnson DM, Jones RN, Erwin ME. The Quality Control Study Group. Anti-streptococcal activity of SB-265805 (LB20304), a novel fluoronaphthyridone, compared with five other compounds, including quality control guidelines. Diagn Microbiol Infect Dis. 1999;33(2):87-91.

Marothu VK, Dannana GS. Spectrophotometric determination of gemifloxacin mesylate in pharmaceutical formulations through ion-pair complex formation. E-J. Chem. 2008;5(3):515-520.
Myung HH, Sang CH, Yoon JC, Jong SJ, Wonjae L. Liquid chromatographic resolution of gemifloxacin mesylate on a chiral stationary phase derived from crown ether. Biomed Chromatogr. 2002;16(5):356-360.

Oh JI, Paek KS, Ahn MJ, Kim MY, Hong CY, Kim IC, Kwak JH. In vitro and in vivo evaluations of LB20304, a new fluoronaphthyridone. Antimicrob Agents Chemother. 1996;40(6):1564-8.

Ramji JV, Austin NE, Boyle GW, Chalker MH, Duncan G, Fairless AJ, et al. The disposition of gemifloxacin a new fluoroquinolone antibiotic, in rats and dogs. Drug Metab Dispos. 2001;29(4 Pt 1):435-442.

Seung IC, Jiyeon S, Min-Su K, Yong-Kweon K, Doo SC. Online sample cleanup and chiral separation of gemifloxacin in a urinary solution using chiral crown ether as a chiral selector in microchip electrophoresis. J. Chromatogr A. 2004;1055(12):241-245.

Sultana N, Arayne MS, Shamim S, Akhtar M, Gul S. Validated method for the determination of gemifloxacin in bulk, pharmaceutical formulations and human serum by RP-HPLC: in vitro applications. J Brazil Chem Soc. 2011;22(5):987-992.

Received for publication on $25^{\text {th }}$ April 2017 Accepted for publication on $06^{\text {th }}$ April 2018 